\title{
Getsemaní: de barrio periférico a núcleo de la escena cultural contemporánea*
}

\author{
Ladys Posso Jiménez ${ }^{1}$ \\ Universidad de Barcelona
}

\section{Resumen}

Antiguamente llamado "El arrabal", por considerársele periférico en relación con otros barrios del casco antiguo de Cartagena de Indias -siendo, así mismo, una expresión peyorativa-, Getsemaní aglutina diversas manifestaciones culturales urbanas, resultando un polo de atracción para artistas locales y extranjeros. En el presente artículo, tomando como marco de referencia barrios artísticos de otras latitudes, pretendemos una aproximación a su actividad cultural.

Palabras clave: barrio artístico, street art, resistencia, arraigo, vida comunitaria.

\begin{abstract}
Formerly called "El arrabal", do to being seen as peripheral to the neighborhoods in the old city of Cartagena. Getsemaní encapsulates diverse urban cultural manifestations, turning the neighborhood into an attraction point to both local and foreign artists. This paper attempts a cultural approximation using as a reference framework other hip neighborhoods around the globe.
\end{abstract}

Keywords: hip neighborhood, street art, resistance, community life, roots.

\footnotetext{
* "Getsemaní: From peripheral neighborhood to modern cultural scene". Recibido: 15 de septiembre de 2013. Aprobado: 14 de octubre de 2013.

${ }^{1}$ Abogada de la Universidad de Cartagena. Máster Oficial en Gestión Cultural de la Universidad de Barcelona (España). Autora de la investigación "Regeneración urbana, valor cultural e inclusión social. El caso del barrio Getsemaní, Cartagena de Indias". e-mail: ladysposso@gmail.com
} 


\section{El fenómeno de los barrios artísticos}

Como antecedentes al fenómeno de los barrios artísticos, se constituyeron los clústeres ó distritos especializados en la bohemia parisina del siglo XIX (barrio latino o Montparnasse y Montmartre), en los que productores y consumidores culturales realizaron aportes para la conformación de lo que un siglo después se conocería como la "contracultura". Estos barrios culturales alternativos originaron la fundación de colonias de artistas que París ha protegido y controlado a través de la planificación y zonificación de la legislación (Evans, 2003: 31). Pero es a partir de 1970, con la redefinición posmoderna de las reglas del $\operatorname{arte}^{2}$ (Rodríguez, 2003), que el fenómeno de los barrios artísticos surge con fuerza en antiguas zonas industriales, o en barrios populares, teniendo casos emblemáticos en el Soho de New York, en los años setenta, y el Marais y La Bastilla, en París, en los ochenta.

El tema es descrito en investigaciones comola de BeatrizGarcía(2004), quien indaga sobre el caso Gran Bretaña (Glasgow y Manchester) y su evolución, con la iniciativa del Estado (modelo top-down), hacia la ocupación de espacios en decadencia, tradicionalmente dedicados a la industria, reutilizándose como atractivos para potencializar a Glasgow (Ciudad Cultural Europea en 1986), e involucrando actividades culturales temporales y permanentes en todas las zonas de la ciudad, así como la creación de infraestructuras culturales.

El modelo de Barcelona, por su parte, implementó grandes eventos (Juegos Olímpicos, 1992) como catalizadores de la renovación de la ciudad, reestructuración física (zonas de desarrollo), combinada con representación simbólica (promoción de la identidad catalana), y forma policéntrica, centros de actividad cultural y negocios en toda la ciudad (Urfalino 1994), utilizando un modelo top-down, en el que la representación cultural resulta dispositivo de marketing. Esto no ha evitado, sin embargo, el riesgo de gentrificación de espacios: se han creado nuevos barrios de superior rango que sustituyen barrios deteriorados, en detrimento de la población local con menos ingresos (Balibrea, 2004).

En Estados Unidos, el tópico es analizado por investigadores como Sharon Zukin (1987-1995) y Currid (2009). El primero describe y analiza cómo artistas empezaron a ocupar grandes espacios fabriles deshabitados, despertando el interés de la administración pública

${ }^{2}$ Desactivación de la oposición entre arte comercial y arte de vanguardia, y por ende, de la oposición espacial de la zonas artísticas de esquema bipolar a multipolar. 
(modelo bottom-up), para su promoción inmobiliaria, ocasionando un incremento en los precios de alquiler que hizo que a artistas y empresas de las industrias culturales les resultara imposible sufragar los costos de permanecer en barrios "de gran riqueza cultural". Currid, por su Parte, lo expone como el "efecto Soho": el barrio neoyorkino pasó de ser un barrio industrial a un enclave bohemio, trasladándose artistas en los años 1960 y 1970 que comenzaron a revitalizarlo con galerías y estudios, generando reinversión e interés en la zona, con nuevos residentes y alzas en los precios de bienes raíces y alquileres, empujando la salida de los artistas y la consolidación de un consumo de élite (Currid, 2009: 374 \& Deutsche, 1984: 92).

El desarrollo de barrios artísticos empieza a tomar forma en América Latina, especialmente documentado en Buenos Aires, con los barrios de Palermo, Chacarita y La Paternal, conformando el distrito audiovisual, en la zona norte y centro de la ciudad (Mignaqui et. al. 2005), y desde el 2009, con la creación gubernamental de distritos temáticos como parte de un proceso de regeneración urbana en el sur de la ciudad: Parque Patricios (tecnológico), Barracas (diseño), La Boca (de las artes). Autores como Rius (2008) reseñan elementos comunes a los barrios artísticos: patrimonio simbólico y cultural acumulado durante tiempo que hace de un espacio un "lugar encantado" para ser usado como escenario de nuevas creaciones, la concentración de creadores, intermediarios e instituciones que forman un denso tejido social, polo emergente de creatividad y la gestación de un estilo de barrio, entre otros (201).

Para el contexto de Cartagena de Indias (Colombia), ciudad turística donde en los últimos años se han llevado a cabo encuentros de mandatarios del continente y distintos eventos y festivales artísticos y culturales de talla internacional, observamos que uno de sus barrios más emblemático, Getsemaní, presenta características que lo hacen interesante para su auscultación (importancia arquitectónica, relevancia histórica, migraciones, atractivo para los artistas) en el contexto del fenómeno de los barrios enclaves artísticos y culturales e indagar, a través de sus dinámicas culturales, si se aproxima a alguna de las tipologías de barrios artísticos enlistados.

\section{Teatros, deporte y tertulia: actividad cultural getsemanicense en el siglo $\mathrm{XX}$}

Para la primera mitad del siglo XX, Getsemaní contó con siete teatros ubicados contiguamente al Claustro de San Francisco: Calamarí, Bucanero, Colón y Variedades (luego Teatro Cartagena), en la calle Larga, Rialto y Padilla, y en la calle del Espíritu Santo, el San Roque, 
convirtiéndose en lugares de encuentro para los getsemanicenses y cartageneros, extendiendo su área de influencia hasta el camellón de los Mártires (lugar de tertulias y cuyos temas predilectos eran el béisbol y la política (Ballestas 2008:63). "Cuando llegaban las fiestas de noviembre, el camellón de los Mártires era el centro de las fiestas, de la ciudad. Al salir de cine, uno se sentaba a conversar, hasta las 3 o 4 de la mañana, sin tomar licor. Era una vida muy tranquila." (Entrevista al comerciante I.S.).

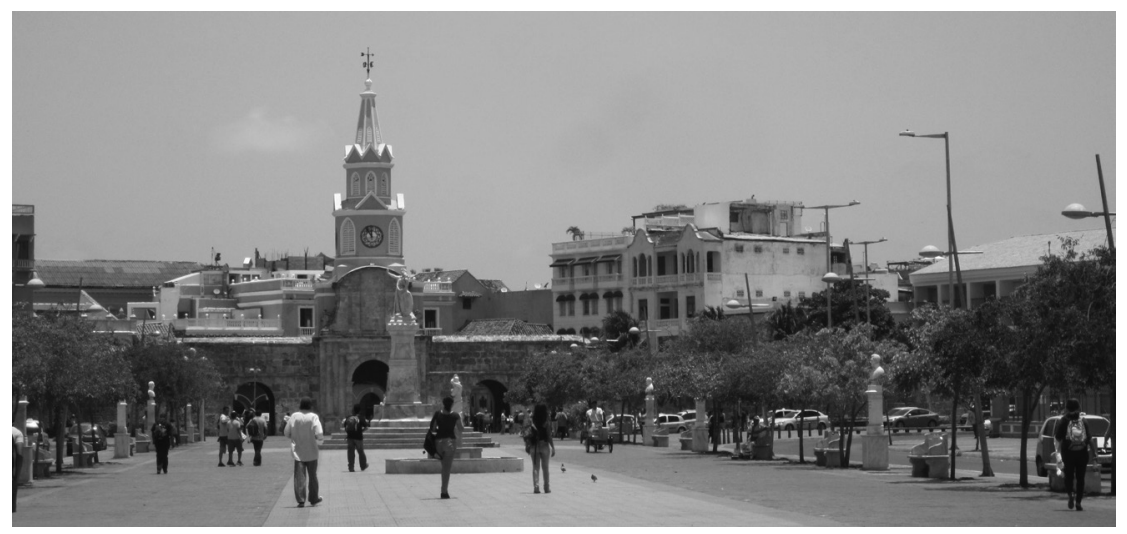

Foto 1. Camellón de los Mártires. Al fondo, la torre del Reloj. Fuente: Posso (2013).

Cada teatro se caracterizaba por una línea de espectáculos y de público: desde cine mudo y combates boxísticos (San Roque), presentación de artistas locales (Padilla), bailes populares en las Fiestas de Noviembre (Rialto), hasta gala de artistas nacionales e internacionales (Cartagena). Los del interior del barrio, Padilla y Rialto, con mayor afluencia de getsemanicenses, mientras que la élite de la ciudad acudía al Teatro Cartagena (Entrevista al historiador M.A.). En las canchas del parque del Centenario se practicaban deportes como el baloncesto y el fútbol; béisbol y sóftbol en la plaza de la Trinidad y en la Avenida del Pedregal, forjándose una gama de deportistas que se destacaron en ligas nacionales e internacionales, como "El Mono" Madrid (basquetbolista). Se conformaron equipos que competían entre sí o con otros barrios, siendo reconocida la rivalidad beisbolística con San Diego, también ubicado en el centro histórico (Getsemaní vs. Águila).

Los juegos de "la peregrina", "la lleva", "las tablitas" y "bola de trapo", aficiones como el "dominó", y diferentes modalidades de juegos de baraja, se hacían en plazas, calles del barrio (con poco flujo vehicular) y escenarios naturales, como la muralla de la avenida del Pedregal. Otra actividad recurrente era retozar a la sombra del atrio de la iglesia de la Trinidad, actividad que aún se mantiene: "Era tan sano 
que bastante gente dormía en el atrio de la iglesia, y nadie se metía con ellos. Ahora usted hace eso y se despierta sin zapatos. La gente era muy unida" (Entrevista a la residente O.P.). El parque Centenario, igualmente, era lugar de encuentro de todas las generaciones, disfrutando los domingos de retretas nocturnas, de las que cuenta el músico A.M., quien fuera miembro de la Banda de Música de la Base Naval: "las hacíamos vestidos de blanco, con el uniforme de la Base Naval. Tocábamos música clásica, los valses de Strauss como el Danubio Azul y los Cuentos de los Bosques de Viena. Iba mucha gente que se ponía alrededor de la banda" (Entrevista).

Para la década de 1980, no obstante, el barrio se verá afectado con el cierre del Mercado Público (con fuerte ligazón con las actividades económicas de los getsemanicenses, este constituía la gran despensa de Cartagena, y en él se fraguaron importantes manifestaciones gastronómicas populares que se irradiaron al resto de la urbe). Por otra parte, la proliferación de actividades relacionadas con el expendio de estupefacientes y la prostitución, sumirían a Getsemaní en una época de estigmatización, que permearía su tejido social (Lemaitre \& Palmeth, 2001; Chica \& Burgos, 2010).

\section{Barrio atractivo}

Inicialmente conocido como "El Arrabal" de Getsemaní, por su condición periférica en la fundación hispánica de Cartagena de Indias, en 1533 -pero posicionándose estratégicamente por su cercanía al puerto-, en él residió una mixtura poblacional de extranjeros, negros libertos y artesanos, y recibiendo una oleada de inmigrantes sirio-libaneses, a finales del siglo XIX, que le dio gran dinamismo comercial. El posterior traslado del Mercado Público y el período de marginalización al que es sometido el barrio ocasiona el desplazamiento de residentes a otras zonas de la ciudad, decreciendo el precio de sus inmuebles.

En la década del 2000, al agotarse la oferta inmobiliaria en los barrios céntricos de San Diego y El Centro, los inversionistas privados se interesan en Getsemaní, teniendo en cuenta su proximidad y precios, dando inicio así a una paulatina restauración, remodelación y construcción de residencias y comercios ${ }^{3}$. En la calle de la Media Luna, por ejemplo, se instalan hospedajes colectivos, cuyos

\footnotetext{
3 Situación avistada por Zukin (1987), al indicar que algunos inversores -"gentrificadores"- aprovechan la disminución en el valor económico de la propiedad, que les ofrece una oportunidad de bajo costo, sobre todo cuando la ubicación en el centro de la ciudad ofrece ventajas (137).
} 
potenciales clientes son turistas extranjeros de bajo presupuesto, "mochileros", tendencia que se ha concentrado e intensificado en esta calle, junto con bares y discotecas. Así mismo, se generó un gran interés por el barrio, sus usos y costumbres, proliferando pequeños hoteles de lujo (boutique) en antiguas residencias readecuadas ${ }^{4}$. Sobre el atractivo que ejerce Getsemaní, comenta el periodista inglés R.N.: "Hay cosas pasando, que también son hechas por extranjeros, "extraños" en el sentido que no son autóctonos, son gente de afuera que ha identificado de alguna manera el barrio como una zona rica en cultura. Les gusta la música, bailar. Todas las cosas culturales sobresalen: Ciudad Móvil, Ruby Rumié, los artistas que llegan buscando espacios más económicos para hacer su arte."

La artista visual bogotana A.E. considera que el atractivo del barrio radica en su potencial, su naturaleza "medio bohemia" que, por sus dinámicas de convivencia, se diferencia de San Diego y El Centro, completamente comerciales y sin identificación: "[...] no sientes que El Centro es tu casa, que te puedes sentar en un andén. En cambio Getsemaní es como un pueblito, con sus niños, sus bicicletas, el burro que sale en la procesión del barrio". A su turno, el artista R.O. piensa que el barrio puede ser interesante para los extranjeros debido a que Getsemaní es la vida en ebullición, siendo atractivo ese "vivir para afuera" que puede resultarles una terapia. Así se advierte cómo se va gestando un proceso de construcción de identidad bohemia, que presenta similitudes con el barrio barcelonés de El Raval, construyéndose hacia el exterior como una marca de barrio poderosa (Rius, 2008).

\subsection{Patrimonio simbólico y cultural}

Sector interesante para turistas, también anima a artistas a fijar su residencia y taller de trabajo ${ }^{5}$. Los precios de arrendamiento y compra de inmuebles que presentaba el barrio antes del 2000 hacían más accesible la residencia para los creadores, que, como afirma Currid (2009: 368), históricamente han buscado residir en barrios con bajos precios de alquiler y amplios espacios para trabajo. El pintor R.O. considera que Getsemaní atrae al artista por el contexto

\footnotetext{
${ }^{4}$ La portada de la revista Diners, en su edición de enero del 2013, titula: "Cartagena. Paraíso para extranjeros". En sus páginas interiores Getsemaní es descrito como "el barrio más tradicional de la ciudad amurallada" (44). Tom Herman, de la firma norteamericana Capital's Extreme MarketsFund (KCP), y director del proyecto Hotel Obra Pía en Getsemaní, lo comparó con el Meatpacking District de Manhattan.

${ }^{5}$ Ejemplo de la atracción del barrio para los artistas se encuentra en Ruby Rumie, con obras basadas en la cotidianidad de sus vecinos.
} 
social que aporta, no encontrándose en otros barrios de la ciudad porque "la vida está ahí, presente" (Entrevista).

La localidad ha sido epicentro de realizaciones audiovisuales nacionales e internacionales: rodaje de películas (de época o contemporáneas), cortometrajes y comerciales. En tanto lugar de encuentro para personajes significativos del país, ha devenido en un espacio atractivo simbólicamente para los artistas, focalizando el espacio ideal para sus obras. Tenemos ahí a Germán Espinosa y su novela Los cortejos del diablo (1970), Gabriel García Márquez, con El amor en los tiempos del cólera (1985) y Del amor y otros demonios (1994), y la poética de Pedro Blas Julio Romero, especialmente con Poemas de Calle Lomba (1984). En inmediaciones de la Plaza de la Trinidad nació el poeta Jorge Artel (representante de la poesía negra colombiana) y vivió la familia Zapata Olivella: los escritores Juan y Manuel, la investigadora y folclorista Delia, que participó en la creación del "Cabildo de Getsemaní”, y su hija Edelmira Massa Zapata, fundadora del grupo de danza "Calenda Getsemaní".

El barrio histórico cartagenero cuenta con uno de los elementos que anota Rius (2008) para la creación del barrio artístico: el patrimonio simbólico y cultural acumulado durante tiempo, que hace de un espacio céntrico e histórico "un lugar encantado", susceptible de ser utilizado físicamente como escenario de nuevas creaciones y como tema en posteriores elaboraciones artísticas (201).

\subsection{Las representaciones simbólicas en el street art getsemanicense}

El colectivo "Pedro Romero Vive Aquí" ha realizado un interesante trabajo de intervención de muros en la calle La Sierpe, convocando a artistas locales para representar al héroe cubano, en un ejercicio de visibilización de la memoria histórica (su ocultamiento por la historia oficial semeja la tradición de exclusión de los getsemanicenses). Del mismo modo, puede verse cómo se han gestado manifestaciones que con-

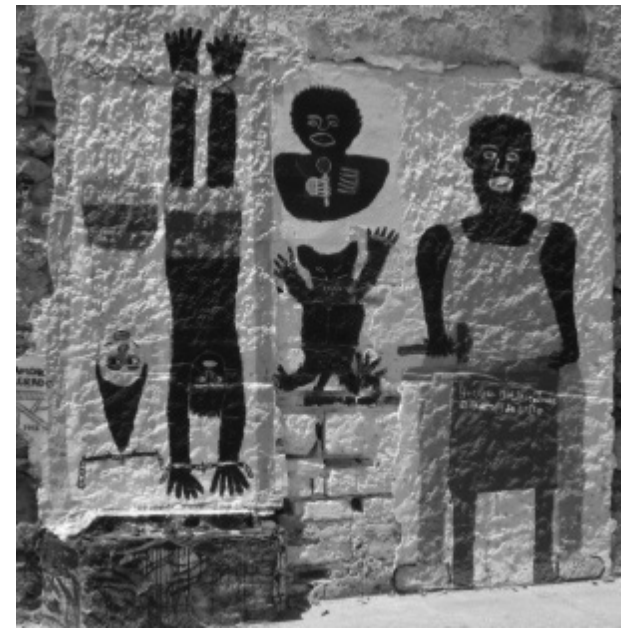

Foto 2. Detalle Calle de La Sierpe. Fuente: Posso (2013 
vocan a la resistencia contra la especulación inmobiliaria, el alza de impuestos y el desplazamiento de los pobladores tradicionales.

Artistas en tránsito realizan trabajos en sus calles: el renombrado artista inglés Fin DAC realizó una de sus obras pictóricas en inmediaciones de la plaza de la Trinidad, y el brasilero Bel-Borda, considerado "El Picasso suramericano", hizo una intervención callejera, con participación de la comunidad getsemanicense, en la calle de La Sierpe. "Más allá del resultado artístico, tenemos la buena onda que el artista le puso a su intervención, la participación comunitaria que generó[...] Bel estaba mostrando el mismo camino que nosotros: la comunidad se apropia del espacio que existe, es una manera de resistirse, pero más activa." (Entrevista a J.N., realizador visual).

El street art ha creado una marca para el barrio, siendo notorio para los residentes tradicionales y nuevos, para los turistas que transitan sus calles atraídos por su arte urbano ${ }^{6}$. En este punto se encuentra semejanza con el barrio El Raval de Barcelona: la presencia de street art constituye una clara reafirmación de la identidad artística o multicultural del barrio (Rius, 2008: 197), combinándose, al igual que en Getsemaní, plantillas, grafitis con denuncias contra multinacionales o especulación inmobiliaria, que, en el caso del barrio cartagenero, se centran en denunciar el alza de impuestos, en remarcar la exclusión de que son objeto sus habitantes, su resistencia, representaciones simbólicas en torno a la gesta independentista y la historia del barrio.

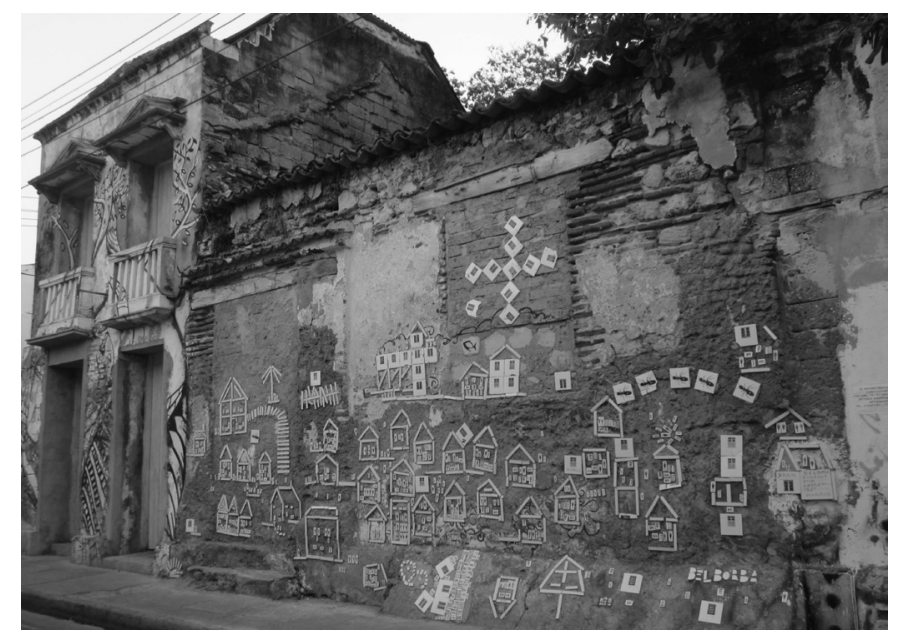

Foto 3. Intervención del brasilero Bel-Borda. Fuente: Posso (2013)

6 La página web This is Cartagena lo reseña el mejor lugar de arte callejero de la ciudad. 
En el otro extremo se encuentra la intervención de los medios de comunicación y agencias de viaje en la manipulación y explotación de la imagen de Getsemaní ${ }^{7}$ que, al igual que en el caso de El Raval y el East Lower Side de New York, tienen un papel decisivo en el proceso de gentrificación: con catálogos y folletos se exhiben representaciones del barrio, destacándolo como el lugar donde la persona puede ser quien quiere ser, con mayor facilidad que en otros barrios, en tanto que sus habitantes luchan por permanecer (Moufarrege, 1982: 69).

\section{Vida cultural barrial: actores relevantes e instituciones}

En este punto se identificará la actividad cultural, como la relacionada con las asociaciones del barrio y la vinculada con la creación artística, plástica y visual. En ese sentido, Getsemaní, por sus dinámicas de convivencia, resulta un ente cultural vivo en sí mismo, que, hasta finales de la década de 1970, contó con gran actividad cultural: en el parque del Centenario, con retretas y concursos musicales; en los teatros, espectáculos variados, y en la Plaza de la Trinidad, con bailes y programas. Con las investigaciones y procesos sociales que la fundación "Gimaní Cultural” desarrolló a mediados de la década del ochenta, Getsemaní retoma sus dinámicas culturales, convocándose a la comunidad y al resto de la ciudad para actividades y proyectos en el barrio.

\subsection{Actividad cultural local}

La Junta de Acción Comunal de Getsemaní promueve continuamente la realización de eventos gestados dentro del mismo barrio: "Plaza encantada", Festival Gastronómico (también conocido como "Jornada de Interculturalidad") y "Getsemaní, Sol de Notas", acompañando la realización de eventos emergentes locales, como el "Off Off Festival", la agenda cultural "Letras desde la Otra Orilla", y el Festival "Mucho más mayo", entre otros ${ }^{8}$.

LaAsociación deVecinos del barrio, con el proyecto “GetCine”, presenta piezas fílmicas de dinámicas locales, como partidos de béisbol que pretenden preservar esa pasión barrial. Participó en "Memorias

\footnotetext{
${ }^{7}$ Los discursos de la "ciudad mostrada" en la construcción de la localidad turística de Cartagena generalmente no corresponden con los de la "ciudad real o vivida" (Ávila, 2008: 16).

8 "Mucho más mayo" tuvo lugar en el 2011, con amplia participación de colectivos y jóvenes artistas, resaltando el componente afro en la conformación de la identidad local.
} 
de la Libertad III" ${ }^{9}$, del Ministerio de Cultura, con la intervención de fachadas, filmación de documentales, exposición fotográfica de la memoria barrial y realización de un censo poblacional, y prevé un Centro de Documentación, con fines de consulta e investigación. Los colectivos "Orgullosamente Getsemanicenses", el centro cultural "Ciudad Móvil", "Por ti Getsemaní" y "Pedro Romero Vive Aquí", participan en el movimiento cultural del barrio y realizan actividades generalmente en el marco de la plaza de la Trinidad, pero que se irradian a todo el barrio, en una tendencia bottom-up, donde la participación gubernamental es mínima.

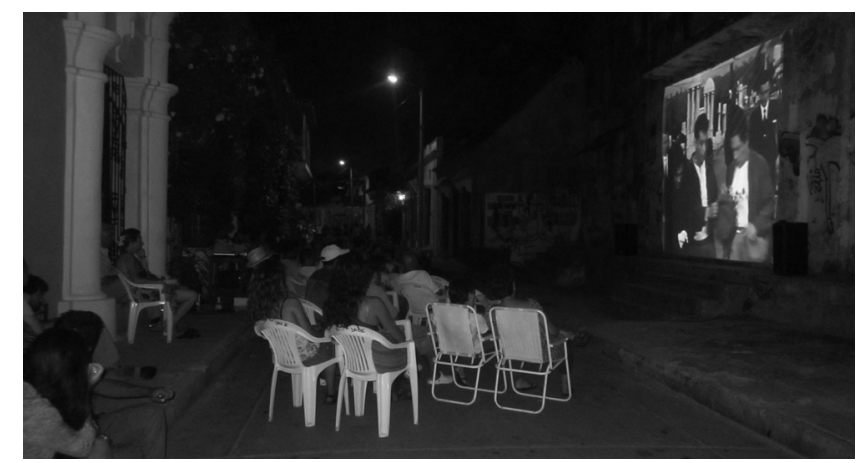

Foto 4. Proyección "GetCine”. (Fachada teatro San Roque). Fuente: Posso (2012)

A nivel turístico, las organizaciones "TuCultura" y "Chitiatour" ofrecen recorridos para pequeños grupos, involucrando productos locales, e intentan insertar a la población getsemanicense en la prestación de servicios, propugnando por un turismo cultural sostenible, parte del segmento conocido como "turismo de nichos" (cf. Caraballo, 2000: 116). La plaza de la Trinidad es un hervidero de manifestaciones culturales: concurren músicos locales y extranjeros, malabaristas, fotógrafos y realizadores; hay proyecciones de películas en el atrio de la iglesia de la Santísima Trinidad. En una tendencia bottom-up, en la Avenida del Pedregal, se desarrollan mercadillos de artículos de segunda mano, juegos infantiles, torneos deportivos de "bola de trapo" y eventos de música salsa.

El artista R.O. considera que el barrio es un organismo muy vivo, que se encuentra muy integrado a la vida, al punto que "Getsemaní es una pelota de fuego en el sentido cultural". En la misma senda el

\footnotetext{
${ }^{9}$ Proyecto cuyo objetivo consiste en generar espacios de debate alrededor de las dinámicas de desplazamiento e invisibilización de las comunidades en la patrimonialización de centros históricos.
} 


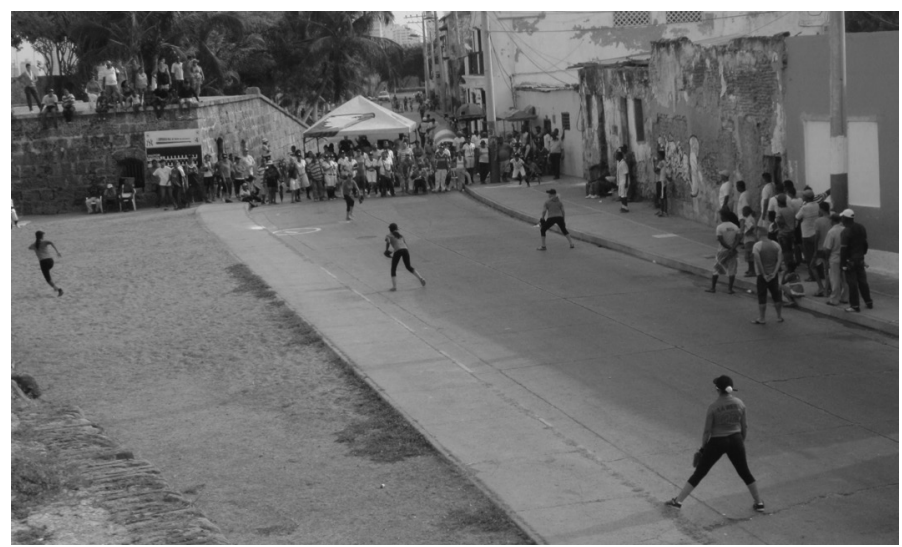

Foto 5. Torneo de Bola de Trapo. Fuente: Posso (2013)

joven L. alude: "Los pasteles ${ }^{10}$ hacen parte de la cultura. La forma como los preparan. La manera como nos relacionamos, eso de rallar el coco en la puerta, sacar los piojos en la calle, eso hace parte de nuestra cultura" (Entrevista). Podemos observar cómo se marca un fenómeno distintivo barrial: la vida en el espacio público como escenario social y capital relacional.

\subsubsection{Fundación "Gimaní Cultural": el Cabildo de Getsemaní como elemento festivo convocante}

La tradición de los cabildos de negros parece ser un fenómeno común en el Caribe, descrito por el folclorista cubano Fernando Ortiz como "asociaciones festivas y de ayuda mutua" que se presentaron durante la época de la Colonia, y que les permitían a los esclavos conservar las costumbres de sus pueblos originarios, lo mismo que cierto desahogo de la represión española, mediante la danza y el goce (Rinaudo, 2011: 2). El surgimiento de los cabildos en Cartagena de Indias data del mismo período, teniendo especial importancia en las Fiestas de la Virgen de la Candelaria, con todo tipo de expresiones culturales y sectores populares (indios y negros), destacándose el cabildo de Bocachica como importante precedente para la legitimación del cabildo de Getsemaní (Gutiérrez, 2011: 303). Con la independencia de la ciudad, en 1811, se marca un hito en las celebraciones festivas: se destaca la ruptura con la dominación española, parodiándola, y el ingreso a la modernidad (Rinaudo, 2011: 3).

\footnotetext{
${ }^{10}$ Plato tradicional de la costa Caribe colombiana, cuyas bases son arroz, carnes y verduras. De elaborada preparación, incluye su recubrimiento y cocción en hojas de bijao (planta tropical).
} 
En el siglo XX se utilizó la figura del Cabildo en Getsemaní como un elemento aglutinador y festivo en el rescate de valores y costumbres del barrio. "Gimaní Cultural" inició en los años 80 una exploración tendiente a recuperar la memoria oral colectiva, acudiendo a los habitantes de mayor edad en búsqueda del sentido identitario del getsemanicense y el restablecimiento del tejido social. En el marco de estas investigaciones, se evidenció la existencia previa de cabildos en los barrios de San Diego y Getsemaní, lo que devino en la realización, en 1989, del "Cabildo de Negros de Getsemaní", en clara alusión a los del siglo XVIII, pero también aludiendo a los "Lanceros de Getsemaní", participantes en la gesta independentista. El líder cívico y miembro de "Gimaní Cultural" M.C., señala que la celebración de este cabildo finisecular obedeció a la necesidad de encontrar un motivo de identificación fuerte, de orgullo comunitario, para el getsemanicense, como un proceso de integración social, más que propiamente festivo, que se ha irradiado a la ciudad (Entrevista).

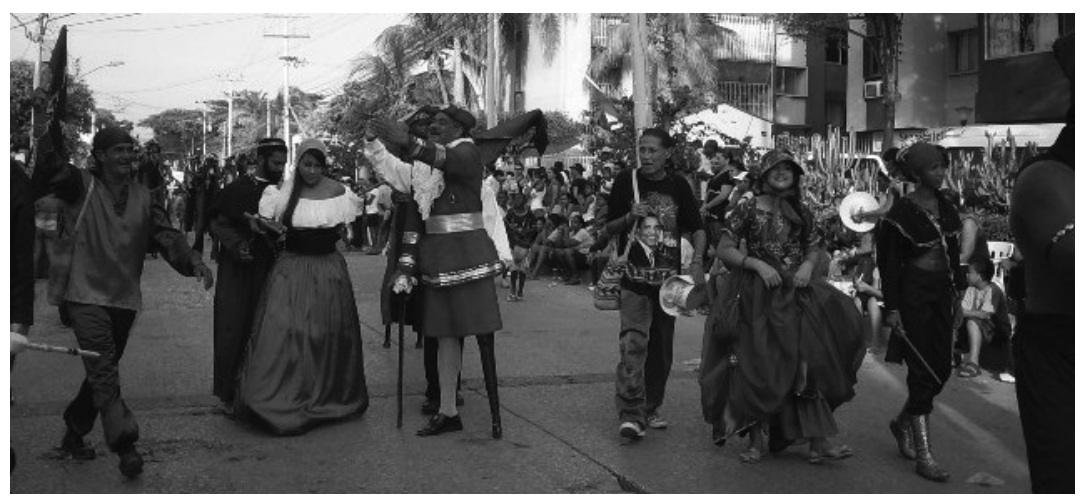

Foto 6. Cabildo de Getsemaní. Fuente: Posso (2009)

El investigador M.M. advierte que constituye la máxima expresión de una representación simbólica, siendo Getsemaní la representación simbólica de la nación colombiana. Anualmente, el Cabildo se celebra en el marco de las Fiestas de la Independencia, el calendario festivo más importante de Cartagena de Indias, "no sólo lo afroamericano, sino también las riquezas de la mixtura y la pluralidad de la cultura latinoamericana" (Gutiérrez, 2011: 307).

\subsubsection{Centro cultural "Ciudad Móvil”: hacia la consolidación de redes}

Como laboratorio creativo, "Ciudad Móvil" abrió sus puertas en diciembre del 2011, con la intención de generar espacios donde los artistas creen y compartan. Lo explica su directora D.C.: "Es 
un experimento de dar un sentido de accesibilidad de la cultura, tanto de los que hacen arte, como de los consumidores, que se ven afectados de la misma manera, de una forma mucho más horizontal" (Entrevista). Con un modelo de auto-gestión, ha extendido sus actividades a la Plaza de la Trinidad, con clases masivas y gratuitas de hip-hop у zumba ${ }^{11}$; sostiene una agenda con formaciones, talleres de pintura para niños del barrio, exposiciones, y procura intercambios locales e internacionales, mediante la consolidación de redes.

"Ciudad Móvil" cuenta con reconocimiento entre los residentes del barrio, pero sin necesariamente encontrar receptividad 0 identificarse con sus espacios: "Le veo protagonismo, ganas y mucha fortaleza, pero sé que no es de los afectos del barrio. Ellos sienten que es para unos artistas que vienen de otra parte, de una gente muy sofisticada. A mí me parece que "Ciudad Móvil" tiene mucha presencia y hace un gran esfuerzo" (Entrevista a la politóloga A.G.). La ausencia de tolerancia ${ }^{12}$ del barrio con el Centro Cultural, al emplear etiquetas como "mochileros" o "hippies", es enlistada como conflicto clásico que radica en la diferencia de habitus entre la neobohemia y los residentes tradicionales (Chalvon-Demersay, 1984). Al respecto, el miembro fundador L.P. indica: "Getsemaní tiene una resistencia y fuerza, y probablemente parte de su resistencia sea resistirse a Ciudad Móvil”, pues el Centro Cultural tiene amplia aceptación entre la población de los barrios ex-céntricos, carentes de espacios culturales (Entrevista).

\subsection{Plaza de la Trinidad: escenario de eventos internacionales}

A partir del siglo XXI se proyectan películas del Festival Internacional de Cine de Cartagena de Indias. La Plaza de la Trinidad sirve de escenario a eventos que no son organizados por la comunidad getsemanicense, como el Festival Internacional de Música de Cartagena, que combina espectáculos gratuitos con lucrativos. Durante las entrevistas a los habitantes de Getsemaní, la utilización de la plaza de la Trinidad en grandes eventos, a modo de etiqueta de marca y de referente estético con simbolismo histórico, pero sin beneficios para la comunidad local, constituyó un reclamo extendido. Esto parece encajar con el dilema de financiación cultural planteado por Bianchini (1993) sobre el efecto de la política cultural en la regeneración urbana, y que se centra en la vacilación entre

\footnotetext{
${ }^{11}$ Disciplina fitness que fusiona baile y rutinas aeróbicas, empleando música salsa, merengue y samba.

${ }^{12}$ Florida (2005) señala que puede ocurrir que los artistas no sean aceptados en una comunidad por valores existentes.
} 
apoyar "efímeramente" actividades como eventos y festivales, o "permanentemente", en la forma de estructuras. En este caso, es evidente que se opta por la primera opción (la administración de la ciudad contribuye financieramente a su realización), pero con el agravante de la ausencia de participación comunitaria activa en estos grandes eventos.

\section{Concentración de creadores e intermediarios}

Un aspecto medular que se advirtió mediante la observación, entrevistas y triangulación de datos, consiste en que creadores de todos los sectores residen en Getsemaní (artes visuales, música, danza, audiovisual, literatura, producción artesanal), pero poco conocen de la existencia de otros; o bien, conociéndose, existe cierto hálito de desconfianza, lo que dificulta que puedan trabajar en redes. En un mapeo de los artistas del barrio, se advierte mayor presencia de artistas en el sector de las artes visuales; sigue en representatividad el sector musical (en ascenso debido al auge de espectáculos en vivo en bares de la zona). Los representantes de estos sectores residen mayormente en las calles del Espíritu Santo, San Juan, El Guerrero, San Antonio, el Pozo y Callejón Angosto. La gestión cultural se encuentra ligada al desempeño de otros sectores como artes visuales o espectáculos en vivo. La arquitectura y el diseño gráfico figuran con varios establecimientos (en calle Larga, Las Palmas, El Carretero y Espíritu Santo), quedando en últimos lugares los sectores de artes escénicas y literarias (Posso, 2013: 114).

Cabe resaltar que estos datos son aproximaciones, si se tiene en cuenta la naturaleza solitaria y silenciosa que en no pocas oportunidades rodea la creación artística, la evasión de algunos artistas a declararse como tales, debido al temor que pueden albergar de no ser exitosos artísticamente (lo que puede conllevar a no publicar o exhibir su trabajo creativo), y el hecho de que muchos artistas no derivan el sustento diario de su obra, sino con actividades económicas paralelas (Benhamou, 1997; Bonet, 2001, 2007).

En la producción artesanal se advierten oficios que datan de la época de la Colonia: la carpintería, la herrería y fundición, con talleres dedicados a la elaboración de productos en madera y establecimientos que trabajan la forja, localizados en la Avenida del Pedregal y las calles de La Aguada, Las Palmas y La Sierpe. En menor proporción, se mantiene la tradición de sastrería que se impuso a mediados del Siglo XX, con establecimientos ubicados en las calles de San Juan, El Guerrero, Media Luna y Avenida del Pedregal. Las zapaterías están, en su mayoría, en la Avenida del Pedregal, calle de 
Las Palmas y Media Luna, al tiempo que en los callejones Angosto y Ancho, la producción artesanal se basa en la gastronomía local (Posso, 2013: 115-116).

En el tópico de la creación colectiva, el fotógrafo M.L. piensa que, conociendo varios artistas residentes en Getsemaní con los que ha hecho trabajos puntuales, podrían hacer más cosas juntos, pues "el barrio tiene todo para ser un barrio de artistas". Por su parte, la directora de "TuCultura" considera que el éxito de su organización radica precisamente en trabajar en redes, formar equipos, generar sinergias con instituciones y emprendedores, artistas y organizaciones culturales (Entrevistas). El artista R.O. considera que el fenómeno de falta de redes se debe a que hasta hace unos años en la ciudad no había una comunidad artística, sino artistas individualmente desarrollando su oficio, pero que existe una mejor disposición en las generaciones jóvenes.

\section{Conclusiones}

Sin llegar aún a la concentración de creadores, artistas, gestores culturales que conformen clústeres, en la estricta acepción de Allan Scott (2010:119), con redes de productores especializados y complementarios que compitan y se complementen entre sí, en Getsemaní se presenta gran creatividad, materializada en mano de obra importante, con diversas cualidades, y en la forja de un estilo de barrio, con diferentes articulaciones y niveles culturales. Probablemente, la creación artística y la formación de redes entre trabajadores de la cultura sigue la suerte de las dinámicas de escisión al interior del barrio, con pugnas entre diferentes organizaciones cívicas. Allan Scott (2010) sugiere que se requiere cierto grado de confianza mutua para la facilitación de la comunicación, especialmente la que tiene que ver con el intercambio de conocimiento tácito en las interacciones del individuo creativo y el medio social, teniendo en cuenta que los individuos que componen cada comunidad suelen interiorizar los elementos de su entorno cotidiano y reflexionar sobre estos esfuerzos creativos, en cierta medida socialmente condicionados $(119,120)^{13}$.

Debido a la heterogeneidad de grupos étnicos que se asentaron en Getsemaní desde la Colonia, se amalgamaron un conjunto de

\footnotetext{
${ }^{13}$ Acorde con lo que señala Rius: "Otro elemento de gran ayuda para los creadores es la presencia de grupos de iguales (creadores que se encuentran en la misma situación) que constituyen una red de solidaridad importante en los comienzos de la carrera, siempre difíciles e inciertos" (2008: 182).
} 
tradiciones y manifestaciones culturales que, a pesar de su condición de extra-radio, se fueron imponiendo y terminaron siendo caldo de cultivo de la identidad cultural cartagenera, en lo que tiene que ver con elementos como la gastronomía, religión, arquitectura, tradición oral y lúdica preservada hasta nuestros días, los hábitos cotidianos, los oficios y objetos tradicionales. La mixtura presente en Getsemaní va gestando una marca de barrio multicultural, con similitud a la de barrios neo-bohemios (Lloyd, 2010; Currid, 2009), con la instalación de bares y tiendas trendy, presencia de mano de obra artesanal, artistas y colectivos de artistas (sin llegar al nivel de clústeres). En recientes años, la población del sector ha cambiado, presentándose el desplazamiento de residentes tradicionales y el ingreso de nuevos habitantes, generalmente procedentes del exterior. Esto marca diferencia con la tendencia de los modelos enlistados en los que la nueva población es integrada por ciudadanos de la misma urbe, pero procedentes de otros barrios. Los superiores niveles de renta es una característica coincidente con el caso getsemanicense.

Más que aproximar los elementos presentes en el otrora "arrabal" a alguno de los ejemplos revisados, corresponde señalar que sus particularidades lo hacen único, y probablemente nos hallemos ante características que guarden relación con rasgos de "distrito cultural", bajo la definición de Rius y Zarlenga (2013: 7), en el que se van creando espacios mixtos de difusión y consumo cultural, teniendo como mampara la renovación urbana y sus bemoles. Pero, sobre todo, en Getsemaní se marcan rasgos que guardan relación con la tipología de "escena cultural", materializada en el refuerzo de la identidad local por agentes culturales en una tendencia bottom-up, que va interesando a cartageneros y foráneos.

Tendencia bottom-up que, como se ha visto, es asumida por organizaciones cívicas y culturales en una permanente promoción de los valores barriales tradicionales. Acciones que rescatan de la invisibilización la problemática de la comunidad getsemanicense acosada por fenómenos como la globalización y la gentrificación, comunes a otros centros históricos del mundo. El papel de la cultura en todo este escenario permite transitar de un estigma a una valorización del patrimonio cultural, en un proceso que puede llevar a la constitución de un barrio cultural sostenible, o bien a un barrio cultural gentrificado, y por lo tanto, privado de este patrimonio y capacidad creativa futura. 


\section{Bibliografía}

Ávila, F. (2008). "La representación de Cartagena de Indias en el discurso turístico", Afrodesc. Cuaderno de trabajo, 끄. 2.

Balibrea, M. P. (2004). "Desacuerdos 3. Sobre arte, políticas y esfera pública en el estado español". En Carrillo J. et al. (Ed.). Barcelona: del modelo a la marca. Barcelona: Arteleku, pp. 261-271.

Ballestas, R. (2008). Cartagena de Indias. Relatos de la vida cotidiana y otras historias. Cartagena de Indias: Casa Editorial S.A.

Benhamou, F. (1997). La economía de la cultura. Montevideo: Trilce.

Bianchini, F. (1993). Urban Cultural Policy in Britain and Europe: Towards Cultural Planning. London: Institute for Cultural Policy Studies.

Bonet, L. (2007). "Aproximación al análisis económico de la oferta y la demanda cultural". En Rubio, J.A. (Ed.). Fundamentos de ciencias sociales aplicados a la gestión cultural. Madrid: Comunidad de Madrid, AGETEC, pp. 75-109.

Bonet, L. (2001). Economía y cultura: una reflexión en clave latinoamericana. Oficina para Europa del Banco Interamericano de Desarrollo.

Bourdieu, P. (1992). Les règles de l'art. Paris: Seuil.

Caraballo, C. (2000). "Centros históricos de América Latina, una polémica de fin de siglo". En Carrión, F. (Ed.). Desarrollo cultural y gestión en centros históricos. Quito: Flacso, pp. 105-119.

Carrión, F. (2000). "El gobierno de los centros históricos". En Carrión, F. (Ed.). Desarrollo cultural y gestión en centros históricos. Quito: Flacso, pp. 5-17.

Chalvon-Demersay, S. (1999). Le triangle du XIVe. Des nouveaux habitants dans un vieux quartier de Paris. Paris: Metailée.

Chica, R. y Burgos, S. (2010). El fantasma urbano de Samir Beetar. Cartagena de Indias: Editorial Universitaria, Universidad de Cartagena.

Currid, E. (2009). "Bohemia as subculture; 'bohemia' as industry: Art, culture, and economic development", Journal of Planning Literature, vol. XXIII, no 4, pp. 368-382.

Deutsche, R. y Gendel, C. (1984). "The fine art of gentrification”, October, no 31, pp. 91-111.

Evans, G. (2003). "The historical evolution of city arts and cultural planning". En Evans, G. (Ed.). Cultural planning. an urban renaissance? Londres-New York: Routledge, pp. 19-44.

Figueroa, H. (2012). “Colombia, atractivo para inversionistas”, El Universal, 28 de enero.

Florida, R. (2005). Cities and the creative class. Routledge.

García, B. (2004). "Cultural policy and urban regeneration in western european cities: Lesson from experience, prospects for the future", Local Economy, vol. 19, no 4, pp.312-326.

Gutiérrez, E. (2011). "Los cabildos de negros en Cartagena de Indias". En Ávila, F. et al. (Ed.). Circulaciones culturales. Lo afrocaribeño entre Cartagena, Veracruz y La Habana. México: Publicaciones de la Casa Chata, pp. 297-310. 
Lemaitre, M. y Palmeth, T. (2001). Getsemaní: el último cono donde desembocan los vientos. Medellín: Lealon.

Lloyd, R. (2010). Neo-bohemian: Art and commerce in the postindustrial city. New York-London: Routledge.

Mignaqui, I. (2005). Clusters creativos en la ciudad de Buenos Aires: estudios de cine y televisión, moda y diseño en "Palermo Hollywood" y "Palermo Soho". 41st ISoCaRP Congress.

Moufarrege, N. (1982). "Another Wave, Still More Savagely Than the First: Lower East Side, Arts, vol. 57, no 1, p. 69.

Nelson, R. (2013). "La lucha para salvar a Getsemaní", Revista Diners, no 514, 1 de enero.

Posso, L. (2013). Regeneración urbana, valor cultural e inclusión social. El caso del barrio Getsemaní, Cartagena de Indias. Tesis de Maestría, Universidad de Barcelona.

Rinaudo, C. (2011). "Fiestas de independencia de Cartagena: dos concepciones de las políticas culturales y del Caribe", Ollin. Revista Del Centro INAH, Veracruz, no 7.

Rius, J. (2008). “Los barrios artísticos como base local de la cultura global. El caso del Raval de Barcelona". En Revista Internacional De Sociología (RIS), LXVI(51), pp. 179-205.

. \& Zarlenga M. (2013). Clústeres culturales, interacciones sociales e innovación cultural. Análisis sociológico de cuatro clústeres culturales de Barcelona. Presentación en el Congreso Catalán de Sociología. Perpignan.

Rodríguez, A. et al. (2007). La sociedad de la cultura. Barcelona: Ariel.

Scott, A. (2010). "Cultural economy and the creative field of the city", Geografiska Annaler. Series B. Human Geography, vo. XCXX, no 2 , pp. 115-130.

Zukin, S. (1987). "Gentrification: Culture and capital in the urban core", Annual Review of Sociology, no 13, pp. 129-147.

Zukin, S. (1995). "Whose cultura? Whose city?" En The cultures of cities. Oxford: Blackwell, pp. 1-47).

\section{Webgrafía}

http://ciudadmovil.wordpress.com/

http://www.eluniversal.com.co

http://getsemanimemoriasdelalibertad.blogspot.com/

http://lonelyplanettraveller.es/ciudades/

http://www.mincultura.gov.co

http://pedroromeroviveaqui.com 